\title{
Study on the Capability Construction of Wetland Community Ecological Tourism Participation- The Case of Luoshijiang Wetland in Dali
}

\author{
Mingqiang $\mathrm{Lu}^{1} \&$ Ning Wang ${ }^{1}$ \\ ${ }^{1}$ Qinhuangdao Branch of Northeast Petroleum University, Qinhuangdao, China \\ Correspondence: Mingqiang Lu, Qinhuangdao Branch of Northeast Petroleum University 112box, Qinhuangdao \\ city 066004, Hebei Province, China. E-mail: 324wxm@sian.com
}

Received: February 5, 2015 Accepted: February 26, 2015 Online Published: March 30, 2015

doi:10.5539/jsd.v8n2p187 URL: http://dx.doi.org/10.5539/jsd.v8n2p187

\begin{abstract}
Wetland ecological tourism is a sustainable traveling form. Community participation is an important part of the development of wetland ecological tourism, while high-quality ecological tourism participation requires certain quality and professional skills among wetland farmers. The study chooses Luoshijiang Wetland Community as the example and elaborates on the contents of wetland community's ability of ecological tourism, periodical arrangements, organization and implementation and so on based on the current situation of the community. Besides, the study is of great importance to enable villagers to take part in the development of tourism smoothly in the wetland community, realize farmers' active maintenance of the wetland's ecological environment, inheritance and development of the wetland community's internal culture, and promote the double sustainability of wetland's ecological environmental protection and ecological tourism.
\end{abstract}

Keywords: community participation, ecological tourism, Luoshijiang wetland

\section{Introduction}

In 1993, International Ecotourism Society defined ecological tourism as "a traveling activity that undertakes dual responsibilities, i.e., protecting natural environment and maintaining local residents' livelihood" (Wu Chucai, 2009; Scheyens, 1999). The definition regards community participation as one important standard for inspecting ecological tourism. Wetland's ecological tourism, as a new and special tourism form, it focuses on protection of ecological environment and environmental education (Wang Lilong, 2009). It is a sustainable tourism form (Wang Jun, 2011). As an important benefit group in the development of ecological tourism site, farmers' high-quality tourism participation in the wetland community is of critical significance for the successful development of wetland tourism, promotion of environmental protection and facilitation of farmers' pursuit of wealth. Nevertheless, high-quality tourism participation requires that farmers in the wetland community should possess certain quality and professional skills (Chen Zhiyong, 2009; Sun Jiuxia, 2009). However, from the situation of many developed wetland ecological tourism communities, we can see that the farmers in the wetland are generally poorly educated with weak skills in tourism industry. It is hard for them to ensure high-quality tourism participation. A number of unexpected problems have appeared. For example, relevant benefit groups' responsibilities are implicit; villagers' subjective positions are not fully highlighted; community demonstrates strong dependence and low tourism participation ability; the benefit coordination mechanism is not complete; profits are not fairly distributed; there is a lack of the ability of analyzing, grasping and applying the market; there is a lack of the ability of understanding their own culture, exhibition ability and inheritance ability so that ecological tourism products are primary, single and inconsistent with tourism resources' values. Villagers lack the awareness of tourism services and ability; the service quality cannot be ensured. Moreover, the little mastery of environmental knowledge and lack of explaining skills restrict from providing tourists with high-quality ecological tourism products. The shocks of external culture intensify the changes of national culture. The tourism products' local design ability is weak. Besides, the tourism products lack or are short of local features. Tourism benefits motivate children's dropout of school. The development of tourism increases the pressure on ecological environment, etc. (Hu Xiao, 2009; Chen biao, 2008; Sun Jiuxia, 2009; Sun Jiuxia, 2010). Therefore, at present, the pertinent construction of wetland community's ability of ecological tourism is of great importance to improving residents' quality, bettering farmers' professional skills and promoting the double sustainable 
development of wetland ecological tourism and environmental protection.

\section{Connotation of Construction of Wetland Community's Ability of Ecological Tourism}

The researches on the construction of community ability started from western nations. The concept appeared in the field of global development in the middle1980s and was transmitted to China in the 1990s (Yang Qian, 2010). Moreover, it received attention from the field of tourism researches in China in the early $21^{\text {st }}$ century and was applied into the practice of tourism planning (Sun Jiu-xia, 2008; Liu weihua, 2002).

In terms of ability construction, there is not unified definition at home and abroad. Newlands (1981) and murray (1995) gave a brief definition of ability construction, i.e., improve personal and collective ability to complete the matters they must complete. Jerry Spiegel (2004) and Casswell (2001) that ability construction included the complex process of introducing more effective technology and resources to change people's ideological tendency and behaviors. Yang Mingliang (2006) started from the perspective of public health and put forward that ability construction should be defined as the process of improving individuals', groups', organization's, community's or society's ability. Wang Ruihua (2008) claimed that ability belonged to the scope of interactions between subjective and objective entities. Construction referred to the process that multi-doers tried to ensure the positive development of things. The researches on the above concept system can be divided into two directions: One is the emphasis that community's ability construction is realized through multi-constructors' cooperation and public right sharing. The other is the focus on the ability itself, i.e., "the process of ability education, cultivation, allocation, use, management and incentive". The study holds the idea that the construction of ecological tourism ability is the process for the purpose of promoting the sustainable development of ecological tourism, carrying out necessary education cultivation, incentive, management and allocation for farmers in the area of ecological tourism, giving full play to farmers' subjectivity, developing farmers' potentials, and improving farmers' ability of taking part in tourism.

In recent year, ability construction has been widely applied in different areas (Qian ning, 2007; Lei ming 2005). It has become an importance term. The introduction of the concept of ability construction has brought new ideas and methods for wetland's ecological tourism planning. However, domestic relevant theories and practices just started up. The construction of wetland community's ecological tourism ability is a systematic project. From the perspective of working contents and procedures, they should include the fundamental survey and evaluation needs, design of ability construction projects, implementation of ability construction and evaluation on ability construction projects.

\section{Introduction of Development of Ecological Tourism in the Case Site and Stakeholders Analysis}

\subsection{Introduction of Development of Ecological Tourism in the Case Site}

Luoshijiang wetland is located in the northern part of Erhai, Dali. It is of great roles for the control on the ecological security of Erhai, Dali. In 2009, Erhai Management Bureau executed wetland recovery project in Luoshijiang River and founded Luoshijiang Wetland Development Co., Ltd. to develop wetland ecological tourism. The wetland community is composed of four natural villages, i.e., Zhaoyi, Louyi, Shaping and Dongshaping. Besides, community self-governance center has been set up. More than $70 \%$ of the villagers are Bai Minorities. The traditional economic income comes from traditional cultivating industry, raising industry external labor. Due to the limited amount of family income, difference in each community's geographical location, traffic conditions and progress of new rural construction, the construction of communities, cultural construction and economic development are imbalanced. At present, the main contents of community participation include reception of ecological sightseeing tourists in the wetland and ecological sightseeing agricultural production in the wetland. In the participation process, there are many problems: inadequate understanding of ecological tourism results in the reducing number of community participants and weak awareness of participation in tourism. The farmers' comprehensive quality is low. As a result, the concept of development is backward. The participation ability is weak. Therefore, it cannot satisfy needs of development of wetland's ecological tourism. The inheritance of ethnical culture is low. Under the shock of modern culture, many old traditions have disappeared. There are only a few channels of community participation. The methods of getting benefits are narrow. Community participation and management is backward. Inside the community, there are no professional community management organizations and personnel. Therefore, for the purpose that the community can take part in ecological tourism at a high quality, the focuses of construction of ecological tourism ability are: (1) Improve local farmers' understanding of ecological tourism so that they can clearly see the development of the tourism industry will improve their living level, expand their horizons and more effectively inherit their ethnical culture. (2) Improve villagers' professional skills and carry out training on professional skills pertinently from various perspectives. 


\subsection{Stakeholders Analysis}

At present, the wetland community ecological tourism main stakeholders include "Erhai Protection \& Management Bureau", "Community self-management center of village committee", "Luoshijiang Wetland Development Construction Co., Ltd" and "Community farmers".

(1) Erhai Protection \& Management Bureau

Erhai Protection \& Management Bureau controls the whole wetland's development on behalf of the government. It is responsible for formulating the macro development strategy. Through making a series of macro guiding plans, combining with the actual situation of each village, it steers the development orientation of Luoshijiang wetland community participation.

\section{(2) Community Self-Management Center of Village Committee}

Community self-management center of village committee is a key part in the organization and management of community participation. It is of great guarantee for the whole community to take part in the construction and development of the company's wetland ecological tourism at a high quality. Its major responsibilities include: 1) Handle the internal contradictions of community participation; 2) Exchange information between company and community, management bureau and community, community and community, external market and community; It is responsible for delivering qualified community talents to Luoshijiang Wetland Development Construction Co., Ltd. and other tourism enterprises; 3) Standardize the operation order of community participation and avoid malicious competition; 4) Protect community residents' benefits in taking part in the ecological tourism; 5) Specific organization and implementation of constructing the ability of community participation; 6) Monitor the environmental protection in community tourism participation.

The personnel in community self-management center of village committee are composed of: Village leaders, Elites and reputable and authoritative personnel in the village and Other volunteers in the village.

(3) Luoshijiang Wetland Development Construction Co., Ltd.

The company is one key part. It undertakes the specific wetland restoration construction, organization and execution of wetland ecological tourism and development of ecological sightseeing agriculture project. Besides, based on its own situation, it should propose the annual elite utilization plan and technical ability requirement plan to community self-management center of village committee.

Main responsibilities and obligations: 1) Propose the annual elite utilization plan and technical ability requirement plan to community self-management center of village committee. 2) Be responsible for providing certain capital for the community ability construction; 3) On the prerequisite of guaranteeing the normal development of the company, expand the working opportunities as many as possible. Accept community residents who are up to the technical requirements to work in the company; 4) Be responsible for paying salary to community personnel who work in the company in full amount; 5) Ensure that Luoshijiang wetland can give its functions into play; 6) Follow all contract signed between farmers;

\section{(4) Community Farmers}

Community farmers are another key part. They are the major entities in community participation. They obtain the ability of community participation through the project of community participation ability construction. Moreover, with the ability, they finally make a fortune. The responsibilities and obligations of community farmers include: 1) Protect Luoshijiang wetland that ensure their living; 2) Take an active part in community participation ability construction project according to their own situation; take an active part in Luoshijiang wetland ecological tourism and ecological sightseeing agricultural development; and obtain corresponding income; 3) Abide by all contracts signed with the company (including Labor Contract, Field Leasing Contract, etc.); 4) Actively publicize ecological tourism and ecological sightseeing agriculture of Luoshijiang wetland; 5) Abide by national laws and "village regulations".

\section{Construction of Ecological Tourism Ability in Luoshijiang Wetland Community}

\subsection{Main Contents of Ability Construction}

Although farmers in Luoshijiang wetland community have high participation passion, their low comprehensive quality restricts the depth and width of community participation. It requires the knowledge construction, consciousness construction and skill construction in tourism participation. Refer to Table 1. 
Table 1 . Contents of ability construction and construction methods

\begin{tabular}{lcc}
\hline Type of ability construction & Contents of ability construction & $\begin{array}{c}\text { Method of ability } \\
\text { construction }\end{array}$ \\
\hline
\end{tabular}

(1) Knowledge of protecting traditional wetland's environment;

(2) Culture of traditional religious festivals and celebrations in Bai Minority, such as

Local

knowledge religious sacrifice, folklore festivals, etc.;

(3) Bai Minority's history and civil legends;

(4) Inheritance of Bai Minority's cultural common sense, geography of villages, language and skills;

(1) Information on the tourism market;

(2) Knowledge of modern tourism enterprises and small tourism enterprises' management;

Knowledge construction

Consciousness construction
(3) External experience.

(1) Basic concept, type and production elements of wetland's agriculture;

wetland's agricultural production knowledge

Laws and system education

Construction of subjective consciousness
(2) Precautions in wetland's agricultural production and wetland protection education;

(3) Production mode of wetland agriculture.

(1) National and local relevant laws and wetland's environmental protection system;

(2) Company's relevant regulations and system;

(3) Regulations in the village and among villagers;

(4) Relevant industrial association system;

(1) Confidence construction;

(2) Construction of independent consciousness; challenge subjective awareness and sense of responsibility among farmers; and regard the community's long-term management and development as its own responsibility;

(3) Construction of subjective development awareness, such as the initiatives to enhance the social relationship inside and outside the community; establish sound partnership with the government and other organizations; make an active use of their own power and intelligence to get rid of poverty; benefit from tourism development; improve living quality.
In the form of lectures: invite wetland's experts to provide training in terms of wetland's environment; invite experts in Bai Minority's culture to provide Bai Minority's local knowledge training.

In the form of lectures, interactions among community's farmers and internal communication; invite tourism experts to provide basic tourism knowledge training.

In the form of lectures, interactions among community's farmers and internal communication; invite experts on wetland's agriculture to provide training;

In the form of blackboard newspapers and wall newspapers; compile relevant laws, rules, regulations in the village and among villagers into a publicity brochure; deliver it to each farmer household.

Publicize in the form of blackboard newspaper, wall newspaper and television media. 
Construction of cohesion

Consciousness of services

Construction of local skills

Construction of service

Skill construction
Construct community's cohesion; re-forge the community's co-construction spirit; establish the community's independent management ability; facilitate community's self-management.

Awareness of commodity economy and awareness of services; responsibilities on the position and awareness of health.

(1) Bai Minority's traditional production skills, such as making of traditional dairy fan;

(2) Performance and exhibition of Bai Minority art;

(3) Traditional sports in Bai Minority;

(4) Traditional food culture in Bai Minority;

(5) Traditional handicrafts, such as orchid's bonsai gardening, cloth weaving, Bai Minority's costumes, etc.

Wetland's ecological tourism guides' explanation skills, etiquette, mandarin and foreign language level, skill of publicity and sales, common sense of safety rescue, etc.

(1) Production technology of wetland's agriculture;

Construction

of wetland's agricultural production skills

Construction of ability of daily wetland maintenance
(2) Comprehensive prevention and treatment technology for wetland's agriculture;

(3) Product marketing of wetland's agriculture;

(4) Explanation of professional skills of wetland's agriculture;

(1) Daily care of wetland's plants and technology of comprehensive prevention from pests;

(2) Clearing and handling of tourism wastes in the wetland;

(30 Daily maintenance of ecological tourism facilities in the wetland;

(4) Daily maintenance of ecological agricultural production equipment in the wetland;
Publicize in the form of blackboard newspaper, wall newspaper and television media.

Publicize in the form of blackboard newspaper, wall newspaper and television media.

Organized by Erhai Protection Management Bureau and executed by the community's

self-management center; invite relevant people in the field of culture, art and religion in Dali to provide professional lectures in the community; internal communications on the making of handicrafts are first carried out; then invite cultural, art and religious experts to provide professional suggestions to perfect the skills and improve the quality.

In the form of experts' explanation, interactions among community's farmers and internal communication; invite etiquette experts to carry out the construction of service skills with tourism experts

In the form of wetland agriculture experts' explanation of skills on site, practical operation, internal communication and organizing villagers to carry out investigations outside.

In the form of experts' explanation, field guidance and internal communication. 


\subsection{Periodical Arrangement of Ability Construction}

The community's ability construction is mainly classified into three periods. The first period lasts for one year. It is the stage of training the farmers' basic knowledge of community participation so that they can possess the preliminary participation consciousness, know the future development direction of the wetland and the project that the community can take part in. At the same time, according to the community's situation, the farmers can choose the direction of family's community participation in the future, accept preliminary skill training, and obtain the primary participation ability. The second period lasts for two years. After farmers choose their future development direction, they accept a wide range of training and obtain high participation ability. The third period lasts for one year. Farmers accept in-depth training so that they can become qualified community participants and become experts in the field that they are good at.

Table 2. Periodical ability construction among community's farmers

\begin{tabular}{cl}
\hline Schedule & \multicolumn{1}{c}{ Arrangement of ability construction } \\
\hline First stage & $\begin{array}{l}\text { Basic knowledge of tourism, construction of subjective consciousness, construction of } \\
\text { cohesion, service consciousness, basic knowledge of modern wetland's agricultural } \\
\text { production, relevant laws and system education, construction of service skills }\end{array}$ \\
Second stage & $\begin{array}{l}\text { construction of subjective consciousness, construction of cohesion, service consciousness, } \\
\text { construction of daily maintenance of wetland; construction of service skills; construction of } \\
\text { Two years }\end{array}$ \\
local skills; construction of the wetland's agricultural production skills
\end{tabular}

\subsection{Organization and Execution of Ability Construction}

The organization and execution of ability construction in Luoshijiang wetland community can be divided into five steps. Refer to Fig. 1.

In the whole process, community self-governance center is always the core of the organization and execution of the whole community's ability construction. Erhai management bureau is the leader of the whole ability construction. Luoshijiang Wetland Development Construction Co., Ltd. is an active promoter of the whole ability construction. The company needs to provide the information of participation ability for the community's ability construction team. Community self-governance center establishes corresponding ability construction project and organizes the execution in time according to the situation of the community's ability and the information needed by the company.

The community's ability construction should emphasize that farmers are the project's subjective entity and stress farmers' wills and benefits as well as local people's participation into the project's planning, execution, management and evaluation on the decision-making in the whole process. Moreover, the local people's subjectivity and sense of responsibility should be established. 


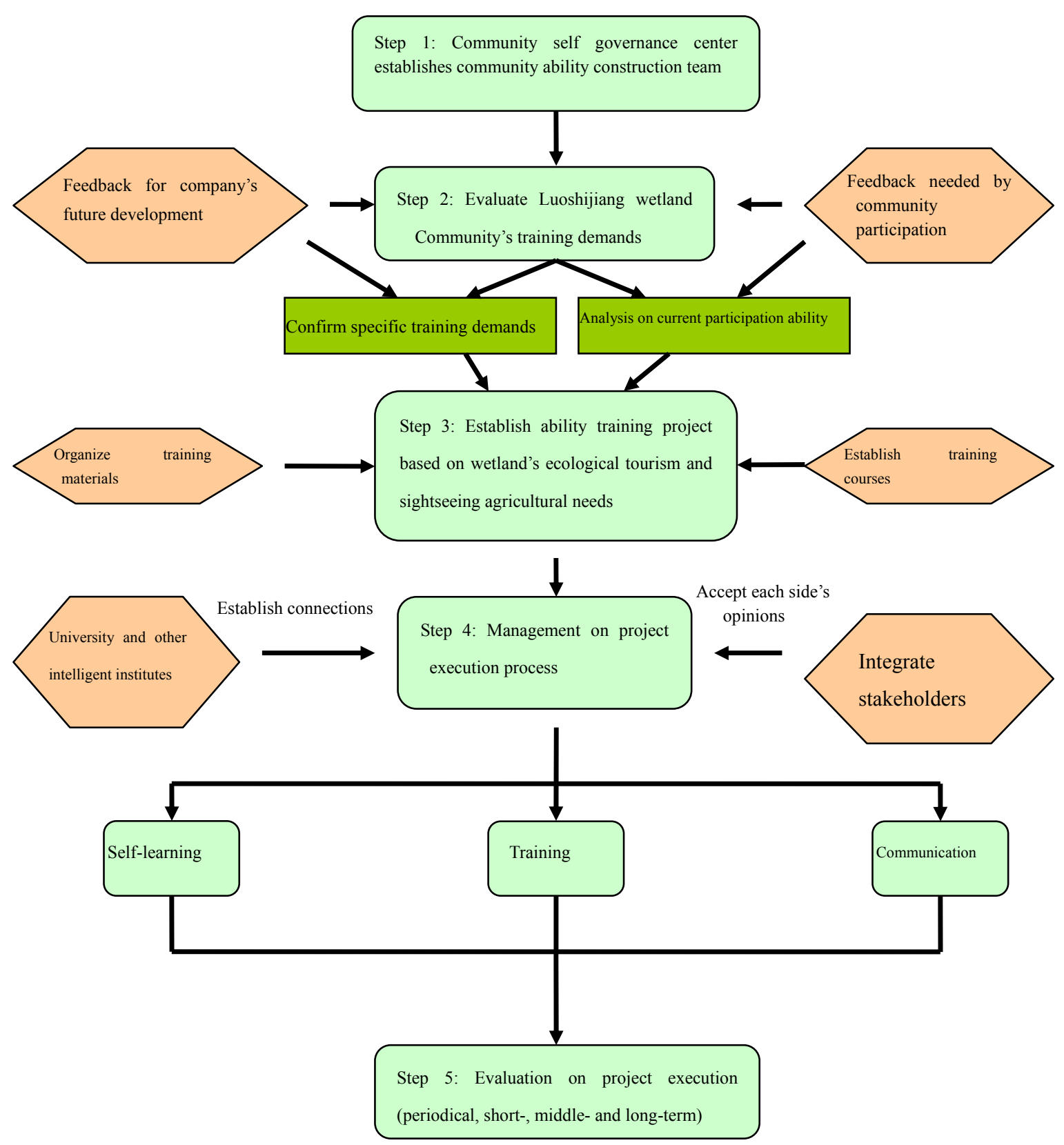

Figure 1. Steps of Organization and execution of Luoshijiang wetland community's ability construction project

Step 1: Community self-governance center establishes specific villager team

Community self-governance center selects elites in the community to take part in the community's ability construction team according to the community's situations. The number of members generally ranges from 3 to 5 . They are responsible for community's ability construction project.

Step 2: Evaluate Luoshijiang wetland's community training demands

Community ability construction team confirms the training demands according to the company's talent demand plan and technical ability and inform each community farmer of the training demands. Each farmer in the community should confirm whether to take part according to their family situations and report the results of the decision to the community ability construction team.

Step 3: Establish ability training project based on wetland's ecological tourism and sightseeing agricultural needs 
Community ability construction team confirms the ability construction project according to the information in each aspect. After the confirmation of the project, community ability construction team establishes materials of ability construction training and training courses, makes a detailed implementation plan, and finally report the final results to Erhai Protection Management Bureau.

Step 4: Management on the project's execution process

Community ability construction team actively contacts relevant intelligent institutes to organize and execute the ability construction project according to the execution plan. In the project execution process, according to each stakeholder's opinions, evaluate and revise the project plan. The project execution should choose one approach with diverse forms and sound effects according to the community's actual demands and project's requirements.

Step 5: Summarize and evaluate the project's execution (periodical, short-, middle- and long-term)

In the process of project execution, summarize the project's execution progress, effects and so on periodically. Evaluate the project's execution at the next stage according to the summarization so as to ensure the project's execution effects.

\section{Concluding Remarks}

The construction of Luoshijiang wetland community's ecological tourism ability is for the purpose of enabling villagers to take part in the development of tourism smoothly, ensuring farmers' benefits in the process, realizing farmers' active participation into the maintenance of ecological environment, inheritance and development of wetland community's internal culture as well as realizing the wetland' ecological environmental protection and sustainable development of ecological tourism industry. The construction of wetland community's ecological tourism ability should be connected with the reality of local environmental protection and the development of ecological tourism. In the relevant training of ecological tourism ability construction, confirm the teaching contents according to villagers' different participation needs and combining with the training situations of different service types, training time and utility. The construction of wetland's ecological tourism ability should take the following four factors into consideration. First, according to relevant position demands, focus on relevant positions' basic knowledge and basic skills so that farmers can master the basic skills required by the positions. Second, pay attention to farmers' hierarchical structure in the wetland. At present, the wetland communities that can develop ecological tourism are mostly located in remote areas. Villagers are generally poorly educated. Therefore, in terms of compilation of training textbooks, easy-to-understand, popular and favorable languages and cases should be adopted to compile training textbooks. In terms of the use of training languages, avoid from using academic languages. Local proverbs, metaphors and so on should be added. Third, in terms of preparation of training contents, the training should deepen from simplicity to complexity. The contents should combine with actual operations related to ecological tourism so that the majority of farmers can know "what to do and what to learn" as well as "enrich whatever is in shortage". Fourth, emphasize that farmers are the main entities in the ecological tourism ability construction project and stress farmers' wills and benefits.

\section{References}

Casswell, S. (2001).Community capacity building and social Policy - what can be achieved. social Policy journal of New Zealand, (17), 22-35.

Chen, B., \& Yang, G. H. (2008). Organizational forms and distribution system of tourism community participation in Meili Snow Mountain, Yubeng. Thinking, 34(3), 127-128. Retrieved from http://www.cqvip.com/QK/80166X/200803/27217973.html

Chen, Z. Y., \& Yang, G. H. (2009). Route selection of the community-dominated tourism development model in poverty-stricken minority region with abundant tourism resources: A case study on Yubeng Zang Minority Community in Meili avalanche scenic spot of Yunnan. Hei longjiang National Series, (2), 52-63. Retrieved from http://wenku.baidu.com/link?url=_L6uFzm12opV5B0vXvouPyZItyFTiJXpSIIyAqpMaBaO77KI8ZC 2Q 2OiICvdToymqDg7e86WidYozpVK3uFbQ74un6HDW0bhUeBPsD2dkEu

$\mathrm{Hu}, \mathrm{X}$. (2009). Study on Rural Ecotourism Capability Building of Ethnic Minority Villages around Nature Reserves - A Case Study of Xishuangbanna National Nature Reserve. Tourism Forum, 2(1), 72-75.

Lei, M. (2005). Ability construction theory - a new development framework. Doctoral dissertations of Party School of the CPC Central Committee, 1-89.

Liu, W. H. (2002). On the theoretical eyesight and subject dimension of community's involving in tourism development. Journal of Hainan University (Social Sciences), 20(2), 98-103. Retrieved from http://www.cqvip.com/QK/80757X/200202/6492089.html 
Murray, M., \& Dunn, L. (1995). Capacity building for rural development in the United States. Journal of rural Studies, (1), 89-97. Retrieved from http://www.sciencedirect.com/science/article/pii/074301679400056F

Newlands, C. A. (1981). Local government capacity building. Urban affairs, 3(1), 4-5.

Qian, N. (2007). A Study of the New Poverty in the Rural Development and the Construction of Community Capacity from the Perspective of Social Work. si xiang zhan xian, 33(1), 20-26. Retrieved from http://www.cqvip.com/QK/80166X/200701/23930953.html

Scheyens, R. (1999). Ecotourism and the empowerment of local communities. Tourism Management, 20, 245-249. Retrieved from http://www.ingentaconnect.com/content/els/02615177/1999/00000020/ 00000002/art00069

Spiegel, J., Bonet, M., Garcia, M., Ibarra, A. M., \& Robert, B. (2004). Tate, and Annalee Yassi Building Capacity in Central Havana to Sustainably Manage Environmental Health Risk in an Urban Ecosystem. EcoHealth Journal Consortium, 11, 120-130

Sun, J. X. (2008). Empowerment theory and the construction of community capability in the development of tourism. Tourism tribune, (9), 21-27. Retrieved from http://www.cqvip.com/QK/97372X/200809/28184767.html

Sun, J. X. (2009). Tourist Anthropology Analysis on Community Tourism and Community Participation. Beijing: The Commercial Press, 90-152.

Sun, J. X. (2010). The impact of ethnic identity on tourist destination community: Based on the role of case studies of different tourism. Journal of Sun Yat-sen University (Social Science Edition), 50(1), 170-177. Retrieved from http://www.cqvip.com/QK/81463X/201001/32718075.html.

Wang, J., \& Wang, Y. (2011). Community Participation Patterns in Ecotourism Development of Wetland Nature Reserve in Jiangsu Province: A Case Study in the Jiangsu Wetland Nature Reserve. Resources Science, 33(11), 2175-2181. Retrieved from http://www.cqvip.com/QK/90831A/201111/39803538.html

Wang, L. L., \& Lu, L. (2009). research progress on wetland ecotourism. Chinese journal of applied ecology, 20(6), 1517-1524. Retrieved from http://www.cqvip.com/QK/90626A/200906/30687355.html

Wang, R. H. (2008). The Strategic Approaches and Their Revelation of Community Self-Organizing Capacity Building in Western Countries. Journal of Henan University (Social Science), 48(3), 43-48. Retrieved from http://www.cqvip.com/QK/97852X/200803/27271334.html

Wu, C. C., Wu, Z. W., Zhang, Q. M., Hu, W. H., \& Tan, Y. M. (2009). An atomization of the definition of ecotourism. Journal of central south university of Forestry \& Technology, 29(5), 1-7. Retrieved from http://www.cqvip.com/QK/96322A/200905/32001304.html

Yang, M. L. (2006). Capacity building: an new important significance concept. Chinese health law, 14(2), 14-16.

Yang, Q. (2010). Research on the Tourism Capacity Building of Chinese Ethnic Community. Dissertation of master degree of East China Normal University, 1-55.

\section{Copyrights}

Copyright for this article is retained by the author(s), with first publication rights granted to the journal.

This is an open-access article distributed under the terms and conditions of the Creative Commons Attribution license (http://creativecommons.org/licenses/by/3.0/). 